\title{
Alpha-Gal Antibody
}

National Cancer Institute

\section{Source}

National Cancer Institute. Alpha-Gal Antibody. NCI Thesaurus. Code C121503.

Any immunog lobulin that recognizes the disaccharide epitope galactose-alpha-1,3galactose (alpha-gal). 